One further point is that the figures refer to occupied beds. When planning for bed numbers they will have to be increased by a factor to allow for bed occupancy rates of less than $100 \%$. In large psychiatric hospitals occupancy rates of $80-90 \%$ can be achieved. However, in DGH units this is neither possible nor desirable. It is not always realised that there are usually no waiting lists of 'cold' cases for psychiatric units, but that admissions are governed almost entirely by emergencies presenting to the Mental Health services. The typical admission is a suicidal and disturbed psychiatric patient seen in the Accident and Emergency Department. Since it is impossible to predict or control the rate at which such patients arrive, bed occupancies in DGH psychiatric units fluctuate widely from day to day. Since it is intolerable to run a unit with no beds (or only one or two) available for admissions, the average occupancy rate may be about $70 \%$ ( $80 \%$ is too high in my opinion). This means that in planning bed numbers in DGH units 30 beds may have to be added for every 70 predicted average occupied beds (and a slightly smaller figure in large psychiatric hospitals). The figures quoted earlier (Robertson via Wing) are all for average occupied beds.

The query on norms arose (at the meeting of Regional Advisers) out of the actions of a Health Authority which appeared to be applying the figures quite rigidly. Fortunately, not all RHAs are being so arbitrary and some are allowing variations in norms according to local psychiatric morbidity. I would recommend that you consult Annexes 1 and 2 of the document Government Response to the Second Report from the Social Services Committee (Session 1984-85): On community care with special reference to adult mentally ill and mentally handicapped people (circulated with letter HN(85)29), which contains the latest DHSS thinking in the matter and which certainly allows for a flexible approach.

These issues have been considered recently by a Working
Party on Bed Norms and Resources set up by the Section for Social and Community Psychiatry of the College, under the Chairmanship of Professor S. R. Hirsch. The resulting document Psychiatric Beds and Resources: Factors Influencing Bed Use and an Approach to Service Planning has been approved by the College and it is hoped to make it more widely available in the near future. This long Report identifies from the literature "a consistent picture which shows a relationship of the prevalence of psychiatric morbidity and resource uptake with social indices of poverty, deprivation and socio-economic status". Clearly there needs to be a very flexible approach to the use of planning 'norms', bearing in mind that some populations (e.g. central city areas) may require a provision of psychiatric beds at a level double that of other parts of the country.

Finally, a note on finance. The modern pattern of the delivery of mental health care is not a cheap option, and yet we have had reports that some Health Authorities have attempted to reduce the overall mental health budget. Members should be aware that such attempts are not condoned by the DHSS and they are to be resisted vigorously. It is a firm ministerial commitment, stated at the joint RCPsych/DHSS meeting and also in Parliament (November 1985), that there should be no reduction in our funds. The savings made on old patterns of mental health care should not be diverted to other branches of medicine, but should be used in the development of new patterns of care. R. G. PRIEST
Registrar

REFERENCE

${ }^{1}$ Wng, J. (1986) The cycle of planning and evaluation. Ch. 6 in The Provision of Mental Health Services in Britain: The Way Ahead (eds G. Wilkinson \& H. Freeman) London: Gaskell (The Royal College of Psychiatrists).

\title{
Honorary Fellowship
}

Nomination of individuals as Honorary Fellows are considered by the Court of Electors at its meeting in February each year. The College may elect, at its Annual General Meeting, any person approved by the Court, whether or not he is a member of the medical profession, who is either eminent in psychiatry or in allied or connected sciences or disciplines or has rendered distinguished service to humanity in relation to the study, prevention or treatment of mental illness or to allied subjects or has rendered notable service to the College or to the Association.

Each nomination for election to the Honorary Fellowship should be made by completing a form obtainable from the Registrar and must be supported by not less than six Members of the College. Completed forms should be sent to the Registrar by 31 December. 